Old Dominion University

ODU Digital Commons

\title{
Pyrocumulonimbus Stratospheric Plume Injections Measured by the ACE-FTS
}

\author{
C.D. Boone \\ Peter F. Bernath \\ Old Dominion University, pbernath@odu.edu
}

M. D. Fromm

Follow this and additional works at: https://digitalcommons.odu.edu/chemistry_fac_pubs

Part of the Organic Chemistry Commons

\section{Original Publication Citation}

Boone, C., Bernath, P., \& Fromm, M. (2020). Pyrocumulonimbus stratospheric plume injections measured by the ACE-FTS. Geophysical Research Letters, 47(15), 1-9, Article e2020GL088442. https://doi.org/ 10.1029/2020GL088442

This Article is brought to you for free and open access by the Chemistry \& Biochemistry at ODU Digital Commons. It has been accepted for inclusion in Chemistry \& Biochemistry Faculty Publications by an authorized administrator of ODU Digital Commons. For more information, please contact digitalcommons@odu.edu. 


\section{Geophysical Research Letters}

\author{
RESEARCH LETTER \\ 10.1029/2020GL088442 \\ Key Points: \\ - Plumes from three \\ pyrocumulonimbus eruptions were \\ measured with the Atmospheric \\ Chemistry Experiment Fourier \\ transform spectrometer \\ - Enhanced stratospheric levels of \\ atmospheric constituents from fire \\ emission and transport were \\ measured for many species \\ - Infrared spectra measured for the \\ associated stratospheric aerosols \\ were strikingly similar for all three \\ events
}

Supporting Information:

- Supporting Information S1

- Data Set S1

- Data Set S2

- Data Set S3

- Data Set S4

- Data Set S5

- Data Set S6

Correspondence to:

C. D. Boone,

cboone@scisat.ca

\section{Citation:}

Boone, C. D., Bernath, P. F., \& Fromm, M. D. (2020). Pyrocumulonimbus stratospheric plume injections measured by the ACE-FTS. Geophysical Research Letters, 47, e2020GL088442. https://doi.org/10.1029/2020GL088442

Received 21 APR 2020 Accepted 14 JUL 2020 Accepted article online 19 JUL 2020

(C)2020. American Geophysical Union. All Rights Reserved.

\section{Pyrocumulonimbus Stratospheric Plume Injections Measured by the ACE-FTS}

\author{
C. D. Boone ${ }^{1}$ iD, P. F. Bernath ${ }^{1,2}$ iD, and M. D. Fromm ${ }^{3}$ iD \\ ${ }^{1}$ Department of Chemistry, University of Waterloo, Waterloo, Ontario, Canada, ${ }^{2}$ Department of Chemistry and \\ Biochemistry, Old Dominion University, Norfolk, VA, USA, ${ }^{3}$ Naval Research Laboratory, Washington, DC, USA
}

\begin{abstract}
The Atmospheric Chemistry Experiment (ACE) is a satellite-based mission that probes Earth's atmosphere via solar occultation. The primary instrument on board is a high-resolution infrared Fourier transform spectrometer (Atmospheric Chemistry Experiment Fourier Transform Spectrometer, ACE-FTS), providing altitude-resolved volume mixing ratio measurements for numerous atmospheric constituents, including many biomass burning products. The ACE mission has observed the aftermath of three major pyrocumulonimbus events, in which extreme heat from intense fires created a pathway for directly injecting into the stratosphere plumes of gaseous and aerosol pollutants. These three events were associated with severe Australian bushfires from 2009 and 2019/2020, along with intense North American wildfires from summer 2017. The ACE-FTS measured stratospheric plumes containing aerosols, enhanced levels of gaseous fire products, and tropospheric air transported into the stratosphere. Infrared spectral features indicate strikingly similar aerosol composition for all three events, characteristic of oxygenated organic matter.

Plain Language Summary The Atmospheric Chemistry Experiment (ACE) is a satellite-based mission for studying the Earth's atmosphere. During the 16+ years of operation for the mission, three extreme fire events were observed that injected gases and smoke particles very high into the atmosphere (near $20 \mathrm{~km}$ in altitude). The amount of gas and the nature of the smoke particles were studied, in an effort to provide insight into the effect of such fires on climate and atmospheric chemistry.
\end{abstract}

\section{Introduction}

Intense fire activity can trigger deep atmospheric convection events, referred to as pyroconvection. Relatively moist, particle-laden, superheated air rising from a fire can, when meteorological conditions permit, generate towering pyrocumulonimbus (pyroCb) clouds (Fromm et al., 2010, 2019). Rapid updraft within the cloud can serve to create an efficient "smokestack" for transporting material from the planetary boundary layer into the upper troposphere and lower stratosphere (Fromm et al., 2005). Severe fires can create sufficiently strong convection for the cloud tops to extend past the tropopause (normally a substantial barrier to transport) and intrude well into the stratosphere (Fromm \& Servranckx, 2003), creating a pipeline for direct injection of biomass burning products into this atmospheric region. The impact of introducing gaseous and aerosol pollutants from fire emissions into the stratosphere is not completely understood but has implications in climate (Peterson et al., 2018) and stratospheric chemistry (Glatthor et al., 2013).

The Atmospheric Chemistry Experiment (ACE) is a satellite-based mission for remote sensing of Earth's atmosphere (Bernath, 2017; Bernath et al., 2005). The measurement technique employed is solar occultation. Using the Sun as a light source, instruments collect a series of atmospheric absorption measurements as the Sun rises or sets from the orbiting satellite's perspective, providing up to 30 measurement opportunities per day. The primary instrument is the Atmospheric Chemistry Experiment Fourier Transform Spectrometer (ACE-FTS), featuring high resolution $\left( \pm 25 \mathrm{~cm}\right.$ maximum optical path difference, $0.02 \mathrm{~cm}^{-1}$ resolution), broad spectral coverage (750 to $4,400 \mathrm{~cm}^{-1}$ ), and a signal-to-noise ratio ranging from 100:1 up to 400:1 (Buijs et al., 2013). There is also a pair of filtered imagers on board (Gilbert et al., 2007), providing atmospheric extinction profiles at 527.11 and $1020.55 \mathrm{~nm}$.

In ACE-FTS processing Version 4 (Boone et al., 2020), volume mixing ratio (VMR) profiles are generated for 44 molecules and 24 subsidiary isotopologues, including a suite of molecules that traditionally experience emissions from biomass burning (Andreae \& Merlet, 2001; Coheur et al., 2007): carbon monoxide (CO), ethane $\left(\mathrm{C}_{2} \mathrm{H}_{6}\right)$, acetylene $\left(\mathrm{C}_{2} \mathrm{H}_{2}\right)$, hydrogen cyanide $(\mathrm{HCN})$, formic acid $(\mathrm{HCOOH})$, methanol $\left(\mathrm{CH}_{3} \mathrm{OH}\right)$, 
peroxyacetyl nitrate $\left(\mathrm{PAN}, \mathrm{C}_{2} \mathrm{H}_{3} \mathrm{NO}_{5}\right)$, acetone $\left(\mathrm{CH}_{3} \mathrm{COCH}_{3}\right)$, acetonitrile $\left(\mathrm{CH}_{3} \mathrm{CN}\right)$, methane $\left(\mathrm{CH}_{4}\right)$, formaldehyde $(\mathrm{HCHO})$, nitrogen dioxide $\left(\mathrm{NO}_{2}\right)$, and methyl chloride $\left(\mathrm{CH}_{3} \mathrm{Cl}\right)$.

\section{Major Pyroconvection Events}

The ACE mission has been collecting scientific measurements since February 2004 (over 16 years to date) and continues to operate well. During this long time span, the mission has captured the atmospheric aftermath from numerous biomass burning events, but three such events stand out, from particularly severe fires that generated plumes of fire emission products well into the lower stratosphere (around $20 \mathrm{~km}$ ). These events are the Black Saturday Australian bushfires from 2009, wildfires in the Pacific Northwest of North America in 2017, and another set of Australian bushfires from 2019/2020.

\subsection{Black Saturday Australian Bushfires}

On 7 February 2009, colloquially referred to as "Black Saturday," a collection of fires devastated southeastern Australia, burning an area covering more than $4,500 \mathrm{~km}^{2}$, with the particularly severe Kilmore East fire burning more than $1,000 \mathrm{~km}^{2}$ in a $12 \mathrm{hr}$ period (Cruz et al., 2012). These intense fires created conditions conducive to a pyroCb "eruption," resulting in the injection of a biomass burning plume into the stratosphere above Australia.

Measurements of the stratospheric smoke plume by the Optical Spectrograph and InfraRed Imager System (OSIRIS) instrument on the Odin satellite (Siddaway \& Petelina, 2011) suggested that plume injection height was between 15 and $17 \mathrm{~km}$ (close to the tropopause height near $16 \mathrm{~km}$ ), in good agreement with radar observations of pyroCb cloud tops near $15 \mathrm{~km}$ (Dowdy et al., 2017), followed by relatively rapid vertical transport above $18 \mathrm{~km}$, after which it remained in the altitude region between 18 and $22 \mathrm{~km}$ from mid-February to mid-June while gradually dissipating.

The stratospheric plume from Black Saturday fires was also studied using measurements from the Microwave Limb Sounder (MLS) on the Aura satellite (Pumphrey et al., 2011). They looked primarily at $\mathrm{CO}$ enhancement but also considered $\mathrm{CH}_{3} \mathrm{CN}$ and $\mathrm{HCN}$. Anomalous behavior in $\mathrm{ClO}$ retrievals was attributed to the presence of enhanced $\mathrm{CH}_{3} \mathrm{OH}$ or $\mathrm{CH}_{3} \mathrm{Cl}$ in the plume.

Another limb-sounding mission that investigated the plume was the Michelson Interferometer for Passive Atmospheric Sounding (MIPAS) instrument on the Envisat satellite (Glatthor et al., 2013). They showed enhanced levels of $\mathrm{CO}, \mathrm{C}_{2} \mathrm{H}_{6}$, and $\mathrm{PAN}$ within the stratospheric plume and, using comparisons to a chemical model, delved into the evolution of $\mathrm{C}_{2} \mathrm{H}_{2}$ and $\mathrm{HCOOH}$ relative to $\mathrm{HCN}$.

The ACE mission captured the plume nearly 3 weeks after Black Saturday. A small number of occultations contained signatures from the plume as ACE measurements swept through the region, but one occultation in particular (sr29848, where "sr" stands for sunrise, and 29,848 is the number of orbits since launch, a unique identifier for the occultation) showed enhanced biomass burning products in a measurement just above $20 \mathrm{~km}$. This occultation was collected on 27 February 2009, 20 days after plume injection into the stratosphere, and was located near latitude $19.8^{\circ} \mathrm{S}$ and longitude $76^{\circ} \mathrm{E}$.

\subsection{Pacific Northwest Event}

On 12 August 2017, wildfires in Washington, USA, and British Columbia, Canada, created a collection of pyroCbs that injected smoke directly into the stratosphere, at altitudes just above the tropopause height near $12 \mathrm{~km}$ (Peterson et al., 2018). Measurements from a combination of satellite sensors were employed to investigate the event, revealing that the mass of aerosols transported into the stratosphere was comparable to a moderate sized volcanic eruption (Peterson et al., 2018).

A study of aerosol measurements from the Stratospheric Aerosol and Gas Experiment III in the International Space Station (SAGE III-ISS) instrument tracked the ascent of the aerosols up to an altitude of $23 \mathrm{~km}$, sufficiently high to persist for about 8 months (Yu et al., 2019). They attributed the magnitude of the ascent to buoyancy from a small fraction of black carbon (BC) among the aerosol particles absorbing sunlight, thereby warming the surrounding air. 
Another study employed a chemical transport model to estimate the radiative forcing associated with this event (Christian et al., 2019), concluding that it imparted a warming in the upper troposphere and lower stratosphere, attributed mostly to efficient absorption from BC.

The first opportunity for the ACE mission to measure the stratospheric plume came almost a month after the event. A small number of occultations contained biomass burning signatures just above $20 \mathrm{~km}$ in early September 2017 as ACE measurements swept through the region. The occultation containing the strongest signature (because it featured the longest path length through the measured plume) was sr75758, measured on 5 September 2017,24 days after plume injection, near latitude $38^{\circ} \mathrm{N}$ and longitude $74.7^{\circ} \mathrm{E}$.

\subsection{Black Summer Australian Bushfires}

During late 2019 through early 2020, colloquially known as "Black Summer," hundreds of wildfires raged through Australia, mainly in the southeast, burning more than $186,000 \mathrm{~km}^{2}$. Peaking in December and January, these widespread fires created at least 18 pyroCb events between 29 December 2019 and 4 January 2020 (Kablick et al., 2020), injecting multiple plumes into the stratosphere. From mid-January through early February 2020, the ACE mission measured several occultations containing biomass burning signatures in the lower stratosphere. For the current paper, an example occultation is selected for comparison with the two previously described major pyroCb events. This occultation is ss 88712 (where "ss" refers to sunset), measured 30 January 2020, 08:42 UTC, between 26 and 32 days after plume injection, near latitude $47.5^{\circ} \mathrm{S}$ and longitude $163^{\circ} \mathrm{E}$.

The Australian Black Summer plume captured by the ACE-FTS (ss88712) was also observed by other instruments. Figure S1a in the supporting information shows measurements of the plume by the Cloud-Aerosol Lidar and Infrared Pathfinder Satellite Observations (CALIPSO) mission (Winker et al., 2009), with the latitude of the ACE-FTS measurement indicated by an arrow. The stratospheric plume is clearly visible, spanning an altitude range from roughly $18 \mathrm{~km}$ to just over $20 \mathrm{~km}$. Figure S1b shows aerosol index (AI) measurements from the Ozone Mapping and Profiler Suite (OMPS) mission (Torres, 2019), collected about $5 \mathrm{hr}$ before the ACE-FTS measurement, with the plume moving slowly northeast. The measured plume, on this day located between Australia and New Zealand, is clearly visible as a large brown splotch on the map. A green star indicates the tangent point (the location of closest approach to the Earth's surface for a measured solar ray) for the ACE-FTS ss88712 measurement, situated within the plume.

\section{ACE Data Issues}

Aerosol levels for Black Summer plumes measured by the ACE-FTS were significantly greater than for the other two cases. For some Black Summer occultations, aerosol absorption was sufficiently strong to impact instrument pointing (which is achieved by finding the center of radiance of the Sun), causing an altitude jump as the instrument moved from looking through the altitude region above the aerosol plume (with the top of the plume in the lower portion of the ACE-FTS field of view) to the altitude region below the plume (with the bottom of the plume located in the upper portion of the ACE-FTS field of view). Although a measurement of the plume is obtained, skipping past the heart of it results in underestimating aerosol extinction as well as VMRs for atmospheric constituents within the plume.

There are multiple ACE-FTS processing versions available for the three events. Version 3.5/3.6 (Boone et al., 2013) results can be used, but the VMR retrievals for some biomass burning products $\left(\mathrm{C}_{2} \mathrm{H}_{2}, \mathrm{C}_{2} \mathrm{H}_{6}\right.$, and $\mathrm{HCOOH}$ ) do not extend high enough in altitude to fully capture enhancements within the plume, unlike later processing versions. In occultations featuring altitude jumps (e.g., where pointing hops from looking above a strongly absorbing aerosol layer to below), imager extinction profiles in this version can exhibit oscillatory behavior (including unphysical negative spikes) within the altitude range lacking measurements. Version 4.0 has problems in the presence of significant aerosols (Boone et al., 2020), and therefore, caution should be exercised when using this version in the analysis of Black Summer plumes. The recently released ACE-FTS processing Version 4.1 has a dramatically reduced sensitivity to aerosols (Boone et al., 2020) and is less likely to yield spurious results when the pointing jumps.

For very strong aerosol extinction, incoming light measured by the visible (VIS) imager (at $527 \mathrm{~nm}$ ) can heavily saturate (i.e., minimal light at that wavelength reaches the detector), which may lead to unreliable results such as negative spikes or an apparent extinction less than that for the near-infrared (NIR) imager, 


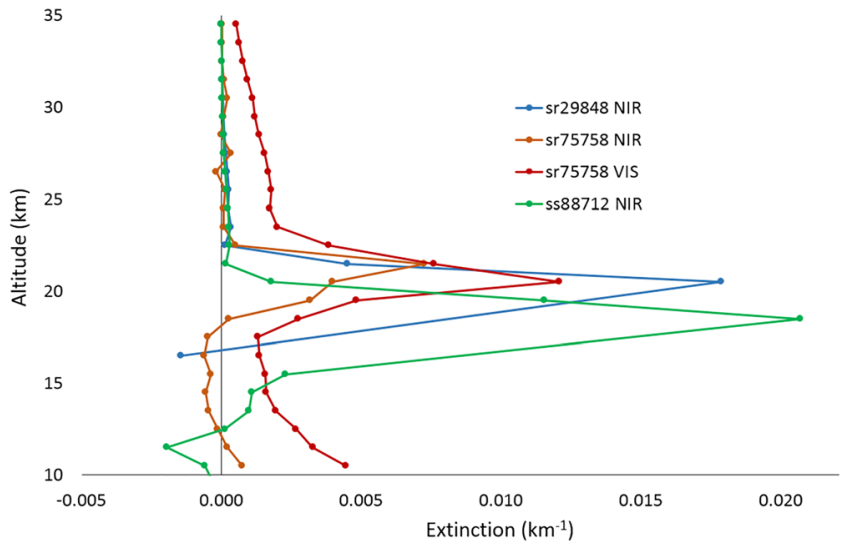

Figure 1. Near infrared (NIR) and visible (VIS) imager data extinction profiles from the ACE mission for three occultations featuring stratospheric plumes from major pyroCb events: sr29848 (from the Australian Black Saturday fires in 2009), sr75758 (from the Pacific Northwest Event in 2017), and ss88712 (from the Australian Black Summer in 2020). regardless of the processing version used. The NIR imager (at $1020 \mathrm{~nm}$ ) is less prone to saturation effects, making it more viable for the analysis of high aerosol loads, whereas the VIS imager is better suited for providing added sensitivity when studying aerosols featuring weaker extinction.

Plume altitudes indicated by ACE-FTS and ACE-imager measurements should be considered a lower limit. The peak altitude will reflect the true height of the aerosol plume only if the plume is close to the tangent point of the measurement. If the plume is in either the foreground or the background relative to the tangent point, it will appear to be at a lower altitude as a consequence of the Earth's curvature (Gordley et al., 2009). The further away from the tangent point the plume resides, the lower in altitude it will seem. There is no means to determine from ACE measurements where along the line of sight the plume is located.

\section{Observations and Discussion}

The current paper employs preliminary Version 4.1 results (Boone et al., 2020), except for four biomass burning products $\left(\mathrm{CH}_{3} \mathrm{OH}\right.$, PAN, acetone, and $\mathrm{CH}_{3} \mathrm{CN}$ ), for which VMR retrievals were pushed to higher altitude specifically for this study in order to capture their enhancement within the plume.

Figure 1 shows imager profiles for the three pyroCb events considered here. The VIS imager profiles for two of the occultations (sr29848 and ss88712) suffer from saturation effects and are therefore not shown. Note that the NIR and VIS imager profiles for sr75758 appear to show a slightly different peak altitude for the plume. There is a "hitch" in measured transmittances near $20 \mathrm{~km}$ for the NIR imager that is not evident in the VIS imager measurements. The source of the differences is unknown but may be connected to the higher propensity for scattering at the lower wavelength of the VIS imager.

As mentioned previously, peak altitudes in the imager measurements serve as a lower limit for the plume height. The heights for the plumes in sr29848 and sr75758 in Figure 1 are consistent with values determined previously (Pumphrey et al., 2011; Yu et al., 2019), suggesting they are near the tangent points of the ACE measurements. The agreement of plume height in ss88712 with the CALIPSO measurement in Figure S1a indicates close correspondence between tangent height and plume for this occultation as well, consistent with the OMPS AI observations in Figure S1b. All three plumes are located well into the lower stratosphere.

Figure 2 shows retrieved VMR profiles for various atmospheric constituents emitted during biomass burning. All exhibit a distinct VMR peak within the plume. Note that in sr75758, comparable (and sometimes higher) VMRs for some molecules below $\sim 16 \mathrm{~km}$ reflect enhancements from something independent from the plume above $20 \mathrm{~km}$ and are therefore not discussed here. Peak stratospheric VMRs in sr75758 are much lower than for the other two examples, but this likely arises primarily from different path lengths through the plumes, which means one cannot directly compare results from different occultations. When comparing different occultations, it is more appropriate to consider relative quantities (e.g., the ratio of a particular molecule's VMR to $\mathrm{HCN}$ ).

Other than $\mathrm{CO}, \mathrm{CH}_{3} \mathrm{OH}$ typically features the highest peak stratospheric VMRs in Figure 2 with $\mathrm{HCN}$ often at comparable levels, followed by $\mathrm{C}_{2} \mathrm{H}_{6}$. Very high $\mathrm{CH}_{3} \mathrm{OH}$ VMRs observed in the Black Saturday occultation (Figure 2a) align with the suggestion that this molecule was impacting MLS measurements of the event (Pumphrey et al., 2011). $\mathrm{CH}_{3} \mathrm{Cl}$, the other molecule mentioned as a potential source of unexpected absorption in the MLS measurements, also appears to have experienced enhancement in these occultations, as shown in Figure S2, but the increase over background levels was roughly 50\%, compared to orders of magnitude for $\mathrm{CH}_{3} \mathrm{OH}$.

$\mathrm{HCOOH}$ shows greater relative abundance in the Pacific Northwest Event (Figure 2b) than the two Australian events. That results in part from differences in emissions from different types of vegetation, but variations in molecular lifetimes in the lower stratosphere (which could deviate significantly from 

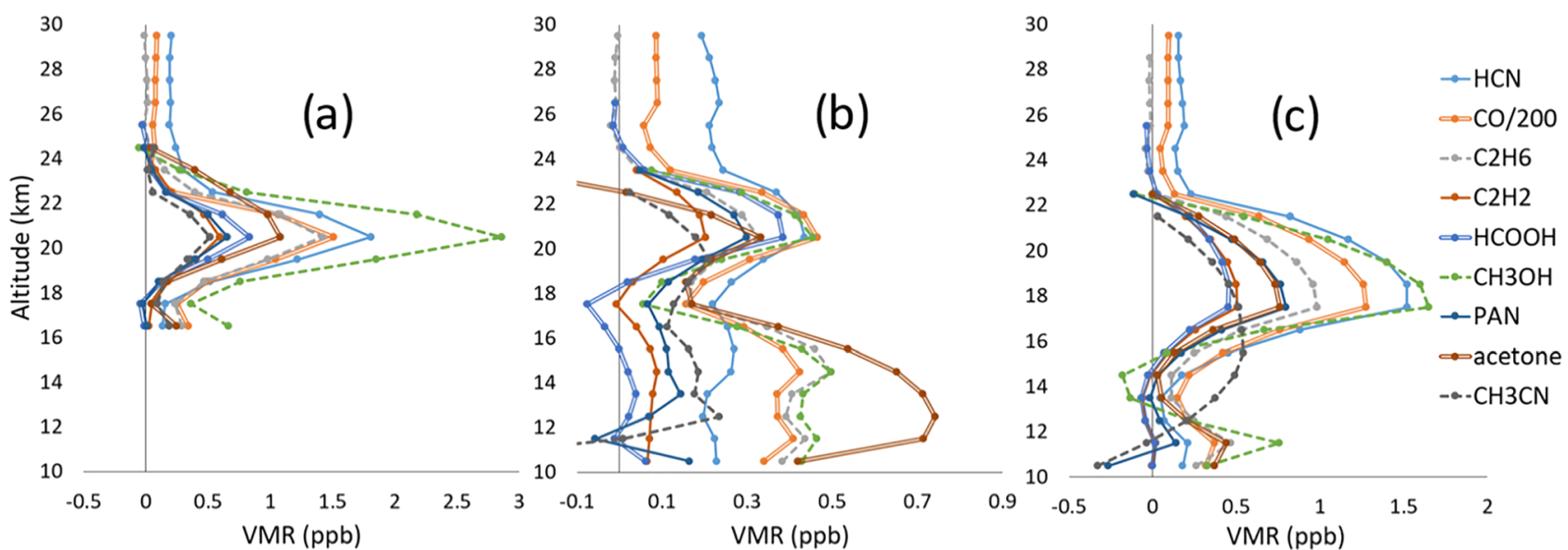

Figure 2. VMR profiles of biomass burning products for occultations featuring a plume in the lower stratosphere: (a) sr29848; (b) sr75758; and (c) ss88712. CO VMR has been divided by a factor of 200 for plotting.

lifetimes experienced in the troposphere and may be sensitive to plume height) will lead to an evolution of relative abundances within the plume over time (R'Honi et al., 2013).

Beyond the nine molecules presented in Figure 2 and $\mathrm{CH}_{3} \mathrm{Cl}$ in Figure S2, other species measured by the ACE-FTS experience perturbations from the pyroCb event. Transport of tropospheric air entrained within the plume into the stratosphere yields enhanced VMRs for molecules that normally feature higher levels in the troposphere than the stratosphere, evident in the significant bumps in $\mathrm{H}_{2} \mathrm{O}$ in Figure $\mathrm{S} 3$, and reduced VMRs for molecules where the opposite is normally true (e.g., $\mathrm{O}_{3}$ ). The two more recent occultations (sr75758 and ss88712) exhibit little difference for $\mathrm{NO}_{2}$, either as a consequence of high tropospheric levels of the molecule from fire emissions or chemical processing of the air within the plume.

$\mathrm{H}_{2} \mathrm{O}$ in the stratosphere serves as a greenhouse gas (Forster \& Shine, 1999), while a pipeline for increasing stratospheric $\mathrm{NO}_{2}$ and chlorine-containing molecules (such as $\mathrm{CH}_{3} \mathrm{Cl}$ ) has negative implications for the health of the ozone layer, the barrier that protects the surface from harmful UV solar radiation (Crutzen, 1979; Santee et al., 2013). However, perturbations in the concentrations of these molecules will generally be localized within the plume and should not induce far-reaching effects but may play a significant role in the nature and chemical evolution of the plume.

A unique perspective offered by the ACE-FTS comes when considering aerosols. Information on particle composition can be deduced from the shape of the spectrum (the locations and relative intensities of different absorption features) in the infrared (Clarisse et al., 2010). The instrument's broad coverage in the infrared provides an opportunity to examine the nature of aerosols emitted from biomass burning. To that end, "residual spectra" are created from ACE-FTS measurements, dividing out all known contributions to the spectra, and what is left represents everything in the measured spectrum that was missing from the calculation, primarily aerosols in the stratospheric plumes. The calculated spectra employ all retrieval results for gas phase molecules, as well as the contribution from the $\mathrm{N}_{2}$ collision-induced absorption, calculated as described in Boone and Bernath (2019), a contribution from $\mathrm{O}_{2}$ collision-induced absorption (Thibault et al., 1997), and far wing absorption from the strong $\mathrm{CO}_{2} v_{3}$ band (Cousin et al., 1985). The measured spectrum is divided through by the calculated spectrum. Only points with a calculated transmittance greater than 0.7 are included in the calculation, to avoid dividing by small values. Results were then averaged into $2 \mathrm{~cm}^{-1}$ wide bins, filtering out values more than 2-sigma (twice the standard deviation) away from the bin average.

Unfortunately, a number of bands for nitric acid $\left(\mathrm{HNO}_{3}\right)$ are missing in the HITRAN 2016 line list (Gordon et al., 2017), which is employed for spectral calculations with the ACE-FTS, and these bands will therefore appear in the residual spectra. The spectral signature from background sulfate aerosols will also appear in the residual spectra. Residual spectra from nearby occultations with similar conditions (in terms of $\mathrm{HNO}_{3}$ and background sulfate aerosols) but lacking a contribution from the stratospheric plume are used to 


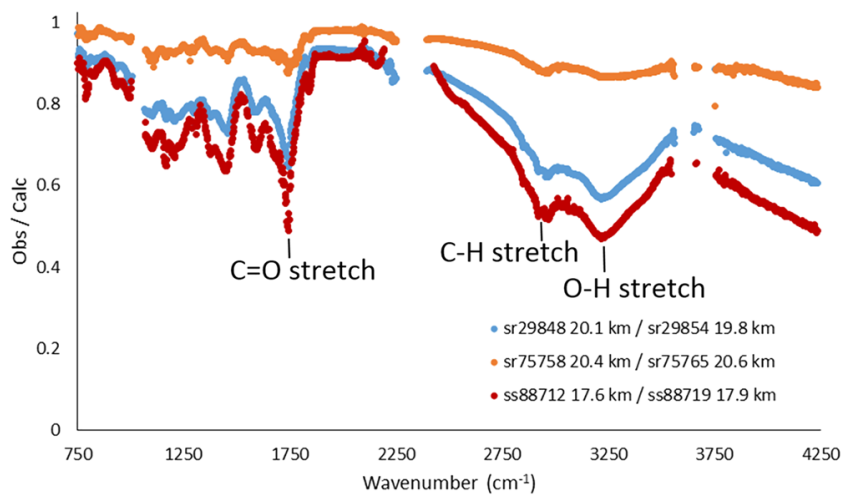

Figure 3. Calibrated residual spectra (observed/calculated) for three measurements containing the signature of stratospheric plumes. The legends indicate the occultation name and tangent height for the measurement containing the plume and the occultation name and tangent height for the measurement used as calibration. Peaks associated with three infrared-active functional groups $(\mathrm{C}=\mathrm{O}$ stretch, $\mathrm{C}-\mathrm{H}$ stretch, and $\mathrm{O}-\mathrm{H}$ stretch) are indicated. generate a rough calibration, dividing out everything except the portion of the spectrum associated with the plume.

Figure S4 shows an example of residual spectra from a measurement of a biomass burning plume (ss88712, $17.6 \mathrm{~km}$ ) along with the plume-free measurement (ss88719, $17.9 \mathrm{~km}$ ) that is used for calibration. Residual spectral features resulting from two $\mathrm{HNO}_{3}$ bands missing from the line list are indicated. The background sulfate aerosol contribution consists of a series of peaks in the lower wave number portion of the spectrum with a maximum absorption of roughly $12 \%$ just below $1,200 \mathrm{~cm}^{-1}$, as well as a broad, shallow feature at higher wave number, peaking near $3,000 \mathrm{~cm}^{-1}$. The $\mathrm{HNO}_{3}$ and sulfate aerosol features cancel when dividing the two spectra to obtain the associated curve in Figure 3, which represents the infrared spectrum associated with the plume itself (primarily from aerosols within the plume, along with any infrared-active gases emitted from the fires that are not included in the calculated spectra).

Figure 3 shows the calibrated residual spectra for the three stratospheric plumes considered in this manuscript. To our knowledge, this represents the first reported measurements of infrared spectra for stratospheric aerosols arising from pyro $\mathrm{Cb}$ events. They all show remarkably similar spectral structure, despite coming from different fires and being sampled at different lengths of time following the pyroCb event. Smaller extinction for sr75758 in Figure 3 is a consequence of fewer aerosol particles along the instrument's line of sight (a function of particle density within the plume and the path length through the plume) than for the other two occultations, but when investigating aerosol composition, it is the shape of the spectrum (i.e., the locations and relative intensities of the various spectral features) that is instructive, not the absolute amount of absorption. Figure S5 shows the spectrum for ss88712 from Figure 3 along with a magnified version of the spectrum for sr75758 to facilitate comparison. The locations and relative intensities of peaks in the spectra display a strong similarity, implying that the aerosols in the two occultations have very similar composition. Note that the divergence between the two spectra toward higher wave number likely results from differences in size distribution, as scattering effects become more significant at higher wave numbers (Eldering et al., 2001).

The wave number positions for absorption features in Figure 3 are characteristic of particular infrared-active functional groups, which provide information on aerosol composition. Each spectrum contains a strong carbonyl $(\mathrm{C}=\mathrm{O}$, double-bonded carbon and oxygen atoms) stretch (i.e., vibration of the bond length) spectral feature near $1,740 \mathrm{~cm}^{-1}$ (Bernath, 2020). Each spectrum also features a peak below $3,000 \mathrm{~cm}^{-1}$ consistent with an alkane (i.e., no double bond on the carbon atom) $\mathrm{C}-\mathrm{H}$ stretch feature (where $\mathrm{H}$ refers to a hydrogen atom). There is also a hydroxyl $(\mathrm{O}-\mathrm{H})$ stretch feature peaked just below $3,250 \mathrm{~cm}^{-1}$, with the location and width suggestive of hydrogen bonding in the aerosol. This feature could alternatively arise from water ice, either from ice deposited on smoke particles or separate aerosols composed primarily of ice. However, in that case one would expect greater variability in peak amplitude relative to the carbonyl stretch spectral feature, indicating that the $\mathrm{O}-\mathrm{H}$ stretch feature is likely associated with the smoke particles. The presence of the $\mathrm{C}=\mathrm{O}$ stretch shows that these particles are oxygenated, which supports this assumption. Other peaks appear in the spectrum below $1,700 \mathrm{~cm}^{-1}$ in Figure 3, associated with additional vibrational modes. For example, there are peaks consistent with methyl $\left(\mathrm{CH}_{3}\right)$ deformation (asymmetrical near $1,450 \mathrm{~cm}^{-1}$ and symmetrical near $1,380 \mathrm{~cm}^{-1}$ ), as well as skeletal $\mathrm{C}-\mathrm{C}$ stretch in the range 1,150-1,250 $\mathrm{cm}^{-1}$ (Bellamy, 1975). Identifying other peaks in the spectrum may provide further clues regarding aerosol composition.

The broad $\mathrm{O}-\mathrm{H}$ stretch feature in Figure 3 is consistent with the infrared measurement of aged wood smoke in Zhong and Jang (2014), attributed in that study to the formation of carboxylic acids. Zhong et al. also observed an increase in the $\mathrm{C}=\mathrm{O}$ stretch absorption as the smoke aged, consistent with oxidation of the aerosol particles. The $\mathrm{C}-\mathrm{H}$ stretch feature indicated in Figure 3 was also noted in their spectrum.

The collection of spectral features in Figure 3 indicates that the aerosols are heavily oxygenated and hydrogenated organic matter, although this only provides insight into the elements comprising the aerosols rather 
than the actual composition. They could be aggregates of organic molecules, organic molecules deposited on particle surfaces, or simply oxygen and hydrogen atoms attached to the exterior of carbonaceous, sooty particles (or some combination thereof). However, the fact that different spectra in Figure 3 feature similar proportions of absorption from different functional groups implies a strong degree of similarity in composition and suggest that heavily oxygenated organic aerosols may represent a characteristic by-product of biomass burning in situations where the fire is intense enough to generate a pyroCb eruption.

Organic aerosols emitted from fires are typically assumed to efficiently scatter solar radiation with minimal absorption, except for BC (composed of almost pure elemental carbon arranged in a honeycomb network of graphitic layers, absorbing strongly at all wavelengths) and brown carbon (aerosols typified by stronger ultraviolet absorption than $\mathrm{BC}$ but assumed to have negligible absorption in the infrared) (Andreae \& Gelencser, 2006). Standard treatment of these aerosols appears to focus on their absorption properties in the visible and ultraviolet, ignoring any impact from absorption in the infrared. Figure 3 shows that pyroCb aerosols contain strong absorption features in the infrared, which should be accounted for when modeling atmospheric effects. At a minimum, infrared absorption by the aerosols will contribute a greenhouse effect, trapping outgoing radiation (Lacis et al., 1992), and could potentially play a role in the "self-lofting" of plumes high into the stratosphere, a mechanism that was previously attributed entirely to small quantities (about 2\%) of BC among the aerosols for the Pacific Northwest Event (Yu et al., 2019).

\section{Conclusions}

ACE-FTS measurements provide a wealth of information on the relative abundances of different biomass burning products, which could be used as inputs in model-based studies probing the impact of introducing relatively large quantities of these species into the lower stratosphere, from the viewpoint of climate and/or stratospheric chemistry. The ACE-FTS provides information on more biomass burning constituents for these stratospheric plumes than any other source. The repercussions of such events are not fully understood but represent an important avenue of inquiry. A shifting climate that promoted increasing numbers of pyroCb events would serve to magnify adverse climate effects, potentially creating a positive feedback loop.

Residual spectra derived from ACE-FTS measurements reveal common characteristics for stratospheric aerosols arising from different pyroCb events: heavily oxygenated organic matter possessing strong absorption features in the infrared. This absorption should be taken into account when considering the impact of these aerosols on climate and on the evolution of the plume (e.g., self-lofting). This infrared signature can be used to differentiate biomass burning plumes from other stratospheric plumes (e.g., sulfate aerosols from volcanic eruptions).

\section{Conflict of Interest}

The authors declare no conflict of interest.

\section{Data Availability Statement}

Atmospheric Chemistry Experiment data employed in this study are provided in the supporting information to this article. CALIPSO data are freely available, as described in Winker (2016). OMPS AI data can be freely obtained as described in Torres (2019).

\section{References}

Funding for the Atmospheric Chemistry Experiment is provided by the Canadian Space Agency. Thanks to Colin Seftor for the OMPS AI map and to the CALIPSO team for the quicklook image.
Andreae, M. O., \& Gelencser, A. (2006). Black carbon or brown carbon? The nature of light-absorbing carbonaceous aerosols. Atmospheric Chemistry and Physics, 6(10), 3131-3148. https://doi.org/10.5194/acp-6-3131-2006

Andreae, M. O., \& Merlet, P. (2001). Emission of trace gases and aerosols from biomass burning. Global Biogeochemical Cycles, 15(4), 955-966. https://doi.org/10.1029/2000GB001382

Bellamy, L. J. (1975). The infra-red spectra of complex molecules (3rd ed.). London: Chapman and Hall. https://doi.org/10.1007/978-94-0116017-9

Bernath, P. F. (2017). The Atmospheric Chemistry Experiment (ACE). Journal of Quantitative Spectroscopy and Radiative Transfer, 186, 3-16. https://doi.org/10.1016/j.jqsrt.2016.04.006

Bernath, P. F. (2020). Spectra of atoms and molecules, $4^{\text {th }}$ Edition, Chap 7, Oxford: Oxford University Press. 
Bernath, P. F., McElroy, C. T., Abrams, M. C., Boone, C. D., Butler, M., Camy-Peyret, C., et al. (2005). Atmospheric Chemistry Experiment (ACE): Mission overview. Geophysical Research Letters, 32, L15S01. https://doi.org/10.1029/2005GL022386

Boone, C. D., \& Bernath, P. F. (2019). Tangent height determination from the $\mathrm{N}_{2}$ continuum for the Atmospheric Chemistry Experiment Fourier transform spectrometer. Journal of Quantitative Spectroscopy and Radiative Transfer, 238, 106481. https://doi.org/10.1016/j. jqsrt.2019.04.033

Boone, C. D., Bernath, P. F., Cok, D., Jones, S. C., \& Steffen, J. (2020). Version 4 retrievals for the Atmospheric Chemistry Experiment Fourier Transform Spectrometer (ACE-FTS) and imagers. Journal of Quantitative Spectroscopy and Radiative Transfer, $247,106939$. https://doi.org/10.1016/j.jqsrt.2020.106939

Boone, C. D., Walker, K. A., \& Bernath, P. F. (2013). Version 3 retrievals for the Atmospheric Chemistry Experiment Fourier Transform Spectrometer (ACE-FTS). In The Atmospheric Chemistry Experiment ACE at 10: A solar occultation anthology (pp. 103-127). Virginia: A Deepak Publishing, edited by Peter F. Bernath.

Buijs, H. L., Soucy, M.-A., \& Lachance, R. L. (2013). ACE-FTS Hardware and Level 1 Processing. In The Atmospheric Chemistry Experiment ACE at 10: A solar occultation anthology (pp. 53-80). Virginia: A. Deepak Publishing, edited by Peter F. Bernath.

Christian, K., Wang, J., Ge, C., Peterson, D., Hyer, E., Yorks, J., \& McGill, M. (2019). Radiative forcing and stratospheric warming of pyrocumulonimbus smoke aerosols: First modeling results with multisensor (EPIC, CALIPSO, and CATS) views from space. Geophysical Research Letters, 46, 10,061-10,071. https://doi.org/10.1029/2019GL082360

Clarisse, L., Hurtmans, D., Prata, A. J., Karagulian, F., Clerbaux, C., De Maziere, M., \& Coheur, P.-F. (2010). Retrieving radius, concentration, optical depth, and mass of different types of aerosols from high-resolution infrared nadir spectra. Applied Optics, 49(19), 3713-3722. https://doi.org/10.1364/AO.49.003713

Coheur, P.-F., Herbin, H., Clerbaux, C., Hurtmans, D., Wespes, C., Carlerr, M., et al. (2007). ACE-FTS observation of a young biomass burning plume: First reported measurements of $\mathrm{C}_{2} \mathrm{H}_{4}, \mathrm{C}_{3} \mathrm{H}_{6} \mathrm{O}, \mathrm{H}_{2} \mathrm{CO}$ and $\mathrm{PAN}$ by infrared occultation from space. Atmospheric Chemistry and Physics, 7(20), 5437-5446. https://doi.org/10.5194/acp-7-5437-2007

Cousin, C., Doucen, R. L., Boulet, C., \& Henry, A. (1985). Temperature dependence of the absorption in the region beyond the 4.3- $\mu$ m band head of CO2 2: N2 and 02 broadening. Applied Optics, 24(22), 3899-3907. https://doi.org/10.1364/AO.24.003899

Crutzen, P. J. (1979). The role of $\mathrm{NO}$ and $\mathrm{NO}_{2}$ in the chemistry of the troposphere and stratosphere. Annual Review of Earth and Planetary Sciences, 7(1), 443-472. https://doi.org/10.1146/annurev.ea.07.050179.002303

Cruz, M. G., Sullivan, A. L., Gould, J. S., Sims, N. C., Bannister, A. J., Hollis, J. J., \& Hurley, R. J. (2012). Anatomy of a catastrophic wildfire: The Black Saturday Kilmore east fire in Victoria, Australia. Forest Ecology and Management, 284, 269-285. https://doi.org/10.1016/j. foreco.2012.02.035

Dowdy, A. J., Fromm, M. D., \& McCarthy, N. (2017). Pyrocumulonimbus lightning and fire ignition on Black Saturday in southeast Australia. Journal of Geophysical Research: Atmospheres, 122, 7342-7354. https://doi.org/10.1002/2017JD026577

Eldering, A., Irion, F. W., Chang, A. Y., Gunson, M. R., Mills, F. P., \& Steele, H. (2001). Vertical profiles of aerosol volume from highspectral-resolution infrared transmission measurements. I. Methodology. Applied Optics, 40(18), 3082-3091. https://doi.org/10.1364/ ao.40.003082

Forster, P. M. D. F., \& Shine, K. P. (1999). Stratospheric water vapour changes as a possible contributor to observed stratospheric cooling. Geophysical Research Letters, 29(6), 10-1-10-4. https://doi.org/10.1029/2001GL013909

Fromm, M., Bevilacqua, R., Servranckx, R., Rosen, J., Thayer, J. P., Herman, J., \& Larko, D. (2005). Pyro-cumulonimbus injection of smoke to the stratosphere: Observations and impact of a super blowup in northwestern Canada on 3-4 August 1998. Journal of Geophysical Research, 110, D08205. https://doi.org/10.1029/2004JD005350

Fromm, M., Lindsey, D. T., Servranckx, R., Yue, G., Trickl, T., Sica, R., et al. (2010). The untold story of pyrocumulonimbus. Bulletin of the American Meteorological Society, 91(9), 1193-1210. https://doi.org/10.1175/2010bams3004.1

Fromm, M., Peterson, D., \& Di Girolamo, L. (2019). The primary convective pathway for observed wildfire emissions in the upper troposphere and lower stratosphere: A targeted reinterpretation. Journal of Geophysical Research: Atmospheres, 124, 13,254-13,272. https:// doi.org/10.1029/2019JD031006

Fromm, M. D., \& Servranckx, R. (2003). Transport of forest fire smoke above the tropopause by supercell convection. Geophysical Research Letters, 30(10), 1542. https://doi.org/10.1029/2002GL016820

Gilbert, K. L., Turnbull, D. N., Walker, K. A., Boone, C. D., McLeod, S. D., Butler, M., et al. (2007). The onboard imagers for the Canadian ACE SCISAT-1 mission. Journal of Geophysical Research, 112, D12207. https://doi.org/10.1029/2006JD007714

Glatthor, N., Höpfner, M., Semeniuk, K., Lupu, A., Palmer, P. I., McConnell, J. C., et al. (2013). The Australian bushfires of February 2009: MIPAS observations and GEM-AQ model results. Atmospheric Chemistry and Physics, 13(3), 1637-1658. https://doi.org/10.5194/acp-13$1637-2013$

Gordley, L. L., Hervig, M. E., Fish, C., Russell, J. M. III, Bailey, S., Cook, J., et al. (2009). The solar occultation for ice experiment. Journal of Atmospheric and Solar-Terrestrial Physics, 71(3-4), 300-315. https://doi.org/10.1016/j.jastp.2008.07.012

Gordon, I. E., Rothman, L. S., Hill, C., Kochanov, R. V., Tan, Y., Bernath, P. F., et al. (2017). The HITRAN 2016 molecular spectroscopic database. Journal of Quantitative Spectroscopy and Radiative Transfer, 203, 3-69. https://doi.org/10.1016/j.jqsrt.2017.06.038

Kablick, G. P. III, Allen, D. R., Fromm, M. D., \& Nedoluha, G. E. (2020). Australian pyroCb smoke generates synoptic-scale stratospheric anticyclones. Geophysical Research Letters, 47, e2020GL088101. https://doi.org/10.1029/2020GL088101

Lacis, A., Hansen, J., \& Sato, M. (1992). Climate forcing by stratospheric aerosols. Geophysical Research Letters, 19(15), 1607-1610. https:// doi.org/10.1029/92GL01620

Peterson, D. A., Campbell, J. R., Hyer, E. J., Fromm, M. D., Kablick, G. P. III, Cossuth, J. H., \& DeLand, M. T. (2018). Wildfire-driven thunderstorms cause a volcano-like stratospheric injection of smoke. npj Climate and Atmospheric Science, 1, 30. https://doi.org/ 10.1038/s41612-018-0039-3

Pumphrey, H. C., Santee, M. L., Livesey, N. J., Schwartz, M. J., \& Read, W. G. (2011). Microwave Limb Sounder observations of biomass-burning products from the Australian bush fires of February 2009. Atmospheric Chemistry and Physics, 11(13), 6285-6296. https://doi.org/10.5194/acp-11-6285-2011

R'Honi, Y., Clarisse, L., Clerbaux, C., Hurtmans, D., Duflot, V., Turquety, S., et al. (2013). Exceptional emissions of $\mathrm{NH}_{3}$ and $\mathrm{HCOOH}_{\text {in }}$ the 2010 Russian wildfires. Atmospheric Chemistry and Physics, 13(8), 4171-4181. https://doi.org/10.5194/acp-13-4171-2013

Santee, M. L., Livesey, N. J., Manney, G. L., Lambert, A., \& Read, W. G. (2013). Methyl chloride from the Aura Microwave Limb Sounder: First global climatology and assessment of variability in the upper troposphere and stratosphere. Journal of Geophysical Research: Atmospheres, 118, 13,532-13,560. https://doi.org/10.1002/2013JD020235

Siddaway, J. M., \& Petelina, S. V. (2011). Transport and evolution of the 2009 Australian Black Saturday bushfire smoke in the lower stratosphere observed by OSIRIS on Odin. Journal of Geophysical Research, 116, D06203. https://doi.org/10.1029/2010JD015162 
Thibault, F., Menoux, V., Le Doucen, R., Rosenmann, L., Hartmann, J.-M., \& Boulet, C. (1997). Infrared collision-induced absorption by ${ }_{2}$ near $6.4 \mu \mathrm{m}$ for atmospheric applications: Measurements and empirical modeling. Applied Optics, 36(3), 563-567. https://doi.org/ 10.1364/AO.36.000563

Torres, O. (2019). OMPS-NPP L2 NM Aerosol Index Swath Orbital V2, Greenbelt, MD, USA, Goddard Earth Sciences Data and Information Services Center (GES DISC), doi:10.5067/40L92G8144IV

Winker, D. (2016). CALIPSO LID L1 standard HDF file-Version 4.10 [data set]. NASA Langley Research Center Atmospheric Science Data Center DAAC. https://doi.org/10.5067/CALIOP/CALIPSO/LID_L1-STANDARD-V4-10

Winker, D. M., Vaughan, M. A., Omar, A., Hu, Y., Powell, K. A., Liu, Z., et al. (2009). Overview of the CALIPSO Mission and CALIOP data processing algorithms. Journal of Atmospheric and Oceanic Technology, 26(11), 2310-2323. https://doi.org/10.1175/2009JTECHA1281.1

Yu, P., Toon, O. B., Bardeen, C. G., Zhu, Y., Rosenlof, K. H., Portmann, R. W., et al. (2019). Black carbon lofts wildfire smoke high into the stratosphere to form a persistent plume. Science, 365(6453), 587-590. https://doi.org/10.1126/science.aax1748

Zhong, M., \& Jang, M. (2014). Dynamic light absorption of biomass-burning organic carbon photochemically aged under natural sunlight. Atmospheric Chemistry and Physics, 14(3), 1517-1525. https://doi.org/10.5194/acp-14-1517-2014 